
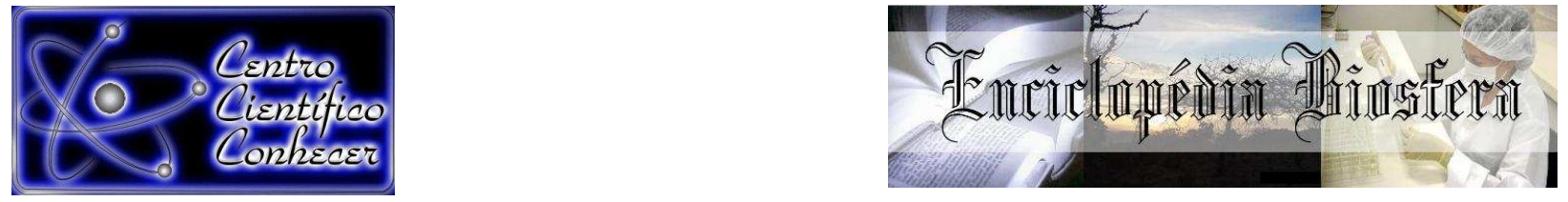

\title{
PERFIL ENZIMÁTICO DE CEPAS DE RIZÓBIOS ISOLADOS DO SEMIÁRIDO
}

Ana Clarice Melo Azevedo de Meneses ${ }^{1}$; Valéria Maria Araújo Silva ${ }^{1}$; Lucas Romão Alves Vasconcelos ${ }^{2}$; Suzana Claudia Silveira Martins ${ }^{3}$; Claudia Miranda Martins ${ }^{3}$

1Doutoranda do Programa de Pós-Graduação em Ecologia e Recursos Naturais, Departamento de Biologia da Universidade Federal do Ceará

${ }^{3}$ Graduando do Curso de Biotecnologia, Departamento de Bioquímica e Biologia Molecular da Universidade Federal do Ceará

${ }^{3}$ Prof $^{\mathrm{a}}$ Doutora do Departamento de Biologia da Universidade Federal do Ceará (claudia.miranda.martins@gmail.com) Fortaleza-Brasil

Recebido em: 03/10/2016 - Aprovado em: 21/11/2016 - Publicado em: 05/12/2016 DOI: 10.18677/EnciBio_2016B_117

A região semiárida nordestina brasileira caracteriza-se por irregularidade espacial e temporal de chuva, com precipitações médias em torno de $800 \mathrm{~mm}$ ao ano e o solo, em sua maioria, classificado como areno-argiloso. Os rizóbios são bactérias diazotróficas que fazem parte dos grupos microbianos do solo, responsáveis pela fixação biológica de nitrogênio. Essas bactérias podem produzir enzimas hidrolíticas, como amilase, lipase e celulase, que atuam em processos biológicos como o crescimento vegetal e o controle de fitopatógenos, bem como na simbiose rizóbio-leguminosa. $\mathrm{Na}$ indústria, essas enzimas têm diversas aplicações, incluindo o setor farmacêutico e alimentício, de cosméticos e de detergentes, têxtil e do papel. Assim, o presente trabalho objetivou avaliar a atividade celulolítica, amilolítica e lipolítica de 42 cepas de rizóbio oriundas da Fazenda Experimental Vale do Curu, região semiárida cearense. As cepas estão depositadas na coleção de culturas de bactérias diazotróficas do Laboratório de Microbiologia Ambiental (LAMAB) do Departamento de Biologia da Universidade Federal do Ceará. A atividade enzimática foi avaliada com base na formação de áreas de degradação em volta da colônia das cepas analisadas. O índice enzimático (IE) foi determinado pela relação entre o diâmetro do halo de hidrólise (em milímetros) (Dh) e o diâmetro da colônia (em milímetros) (Dc) de cada rizóbio. Das estirpes testadas 97,62\% apresentaram atividade amilolítica, enquanto que $19 \%$ produziram a enzima celulase e, 16,67\%, lipase. Tais resultados indicam que o semiárido é um ambiente propício à obtenção de rizóbios potencialmente produtores de enzimas hidrolíticas, principalmente amilase.

PALAVRAS-CHAVE: bactérias diazotróficas, índice enzimático.solo.

\section{PROFILE RHIZOBIA STRAINS OF ENZYME ISOLATED FROM A CEARÁ SEMIARID REGION}

\begin{abstract}
The Brazilian northeastern semiarid region is characterized by spatial and temporal irregularity of rainfall, with average rainfall around $800 \mathrm{~mm}$ per year and the soil, ENCICLOPÉDIA BIOSFERA, Centro Científico Conhecer - Goiânia, v.13 n.24; p.1263 2016
\end{abstract}


mostly classified as sandy clay. The Rhizobia are diazotrophs forming part of the soil microbial groups responsible for nitrogen fixation. These bacteria can produce hydrolytic enzymes such as amylase, lipase and cellulase, which act on biological processes such as plant growth and controlling plant pathogens and the Rhizobiumlegume symbiosis. In undústria, these enzymes have several applications, including pharmaceutical and food industry, cosmetics and detergents, textiles and paper. Thus, this study aimed to evaluate the cellulolytic activity, amylolytic and lipolytic 42 rhizobia strains originated from the Experimental Farm Vale do Curu, from Ceará semiarid region. Strains are deposited in the collection of cultures diazotrophs Environmental Microbiology Laboratory (LAMAB) of the Department of Biology of the Federal University of Ceará. The enzymatic activity was evaluated based on the formation of degradation areas around the colony of strains analyzed. The enzymatic index (EI) was determined by the ratio between the hydrolysis halo diameter (in millimeters) (Dh) and the diameter of the colony $(\mathrm{mm})(\mathrm{Dc})$ of each rhizobia. $97.62 \%$ of the strains tested showed amylolytic activity, while $19 \%$ produced the cellulase enzyme and $16.67 \%$, lipase. These results indicate that the semiarid region is an environment conducive to obtaining potentially rhizobia producers of hydrolytic enzymes, mainly amylase.

KEYWORDS: soil, diazotrophs, enzymatic index.

\section{INTRODUÇÃO}

O semiárido do nordeste brasileiro apresenta características como irregularidade espacial e temporal de chuvas, temperaturas médias, ao ano, na faixa de $23^{\circ} \mathrm{C}$ a $27^{\circ} \mathrm{C}$, precipitações médias anuais em to rno de $800 \mathrm{~mm}$ e geralmente com solos pobres em matéria orgânica (SUDENE, 2016). Essa região caracteriza-se ainda por vegetação típica de caatinga (LIMA et al., 2012).

O solo é um ambiente complexo e dinâmico (MOREIRA \& SIQUEIRA, 2006), onde o maior número e a maior diversidade microbiana ocorrem na zona mais próxima das raízes das plantas em crescimento, a rizosfera, devido à liberação de exsudados (COMPANT et al., 2010). Dentre os grupos microbianos presentes no solo, destacam-se os rizóbios, bactérias Gram-negativas, com ampla diversidade fenotípica e taxonômica (FERNANDES JÚNIOR et al., 2012).

Os rizóbios conseguem captar o nitrogênio atmosférico e convertê-lo em formas que as plantas e outros organismos conseguem assimilar, sendo assim denominados micro-organismos diazotróficos ou bactérias fixadoras de nitrogênio nodulíferas (MOREIRA \& SIQUEIRA, 2006). A formação de nódulos pode ocorrer nas raízes e/ ou nos caules de leguminosas (FERNANDES JÚNIOR et al., 2012; SABINO et al., 2012; LONGATTI et al., 2013). As bactérias que fixam nitrogênio $\left(\mathrm{N}_{2}\right)$ tem importância econômica (agrícola e florestal) e ecológica (MOREIRA \& SIQUEIRA, 2006).

A habilidade de produzir enzimas diferentes para utilizar vários substratos orgânicos é uma característica importante de rizóbios (KUMARI et al., 2010). Estudos com cepas dessas bactérias relataram a produção das enzimas amilase (OLIVEIRA et al., 2006; KUMARI et al., 2010; FERNANDES JÚNIOR et al., 2012; CHANDRA, 2016), celulase e lipase (OLIVEIRA et al., 2006; KUMARI et al., 2010). As enzimas hidrolíticas têm papel crucial no processo de infecção das raízes de leguminosas pela bactéria, despertando o maior interesse na seleção de cepas de rizóbios com atividade enzimática (OLIVEIRA et al., 2006; ROBLEDO et al., 2008). 
Enzimas como a amilase e a lipase atuam no desenvolvimento vegetal e no controle biológico de fitopatógenos (SOUSA et al., 2008). Amilases podem ser obtidas de fontes microbianas, de animais e de vegetais (MAGESWARI et al., 2012), entretanto, quando comparada com os recursos animais e vegetais, essas enzimas são obtidas principalmente por via microbiana (JARALLA et al., 2014; SAMPATHKUMAR, 2014; SILVA et al., 2015b; SILVA et al., 2015a). O potencial microbiano para a produção de enzimas hidróliticas é de suma importância por seu papel ecológico, além de ser acessível e eficiente e com menor custo para obtenção (PAUL, 2016).

As celulases são responsáveis pela degradação da celulose, que é um polímero de estrutura complexa, principal componente dos vegetais e, no solo representa fração significativa de carbono orgânico (SATHYA \& USHADEVI, 2014; FLORÊNCIO et al., 2012). A celulose faz parte da lignocelulose, matriz complexa que confere, à planta, ao longo de sua vida, resistência a agentes patogênicos e herbívoros, bem como uma estrutura íntegra (CRAGG et al., 2015). Em estudo realizado em ambiente semiárido SILVA et al. (2015b) destacaram nos resultados de suas pesquisas com actinobactérias a produção de celulase em $75 \%$ das cepas avaliadas. Esses autores ressaltam o bioma Caatinga, como um nicho promissor para a obtenção de micro-organismos que produzam enzimas hidrolíticas capazes de degradar substratos complexos.

As amilases degradam o substrato amido, um composto orgânico formado por amilose e amilopectina, que faz parte da composição da massa vegetal e da massa animal e, é decomposto por micro-organismos no solo. Considerando a reserva vegetal, o amido é o composto orgânico mais importante, no que diz respeito ao armazenamento de energia (VAN DER SAND et al., 2014).

As lipases, assim como as amilases, são obtidas principalmente por fontes microbianas, incluindo as bactérias, como Pseudomonas fluorescens e Pseudomonas putida (STOYANOVA et al., 2012). Os lipídios, que assim como o amido, compõem a massa animal e a fitomassa, e podem ser degradados por microorganismos no solo como as bactérias. O lipídio cutina pode ser degradado por bactérias fixadoras de nitrogênio do gênero Azotobacter (MOREIRA \& SIQUEIRA, 2006).

Além do papel ecológico, as enzimas hidrolíticas destacam-se quanto ao aspecto biotecnológico. As celulases são utilizadas em setores industriais como têxtil e do papel (PAIVA \& SÁ-PEREIRA, 2008), enquanto que as amilases são aplicadas na indústria farmacêutica, alimentícia, têxtil, e do álcool (MAGESWARI et al., 2012). As lipases são empregadas na indústria têxtil, alimentícia, de cosméticos, de detergentes, do papel, entre outras aplicações (HASAN et al., 2006). É válido destacar também a importância da obtenção de novas fontes microbianas produtoras de enzimas com potencial biotecnológico, atendendo diversas áreas da indústria.

A análise da atividade enzimática dos rizóbios oriundos do semiárido cearense pode contribuir na seleção de bactérias que apresentem potencial relevante na produção de enzimas hidrolíticas, descatando-se a atuação desse grupo de micro-organismos em processos ecológicos no bioma Caatinga. $O$ presente estudo objetivou avaliar a atividade celulolítica, amilolítica e lipolítica de 42 cepas de rizóbio oriundas da Fazenda Experimental Vale do Curu, região semiárida cearense. 


\section{Local de coleta}

\section{MATERIAL E MÉTODOS}

As cepas de rizóbios foram obtidas a partir de amostras de solo rizosférico coletadas na Fazenda Experimental Vale do Curu, localizada no município de Pentecoste, Ceará. Na área de estudo o solo é classificado como Neossolo Flúvico (EMBRAPA, 1999). O município de Pentecoste fica situado nas coordenadas 3 47' 34 " de latitude sul e $39^{\circ} 16^{\prime} 13^{\prime \prime}$ de longitude oes te de Greenwich a uma altitude de $60 \mathrm{~m}$.

\section{Micro-organismo}

Foram selecionadas 42 cepas de rizóbios, previamente isoladas, autenticadas e caracterizadas fenotipicamente por SOUSA et al. (2014). Referidas cepas são mantidas em tubos de ensaio com meio YMA ("yeast manitol agar") inclinado, a ${ }^{\circ} \mathrm{C}$, formando a coleção de culturas de bactérias diazotróficas do Laboratório de Microbiologia Ambiental (LAMAB) do Departamento de Biologia da Universidade Federal do Ceará (UFC).

\section{Atividade enzimática}

As cepas de rizóbios denominadas L31, L32, L33, L35, L36, L37, L38, L39, L40, L41, L42, L43, L46, L47, L48, L49, L51, L52, L53, L54, L56, L59, L60, L62, L63, L64, L65, L66, L67, L69, L70, L71, L72, L73, L74, L76, L77, L78, L79, L80, L81 e L82 foram analisadas quanto à produção de celulase, amilase e lipase. Foram realizados dois ensaios independentes em quadruplicata, inoculando-se as cepas na forma de spots. Com o auxílio de um paquímetro $(\mathrm{mm})$ posicionado no reverso das placas, mediram-se os diâmetros das colônias e dos halos de degradação.

\section{Atividade celulolítica}

A produção de celulase foi avaliada de acordo com o método proposto por HANKIN \& ANAGNOSTAKIS (1977) e CHARBONNEAU et al. (2012). As cepas de rizóbios foram inoculadas em meio composto da seguinte forma: carboximetilcelulose $\left(5,0 \mathrm{~g} \mathrm{~L}^{-1}\right)$ (exclusiva fonte de carbono), $\mathrm{MgSO}_{4}\left(0,5 \mathrm{~g} \mathrm{~L}^{-1}\right), \mathrm{KCl}$ $\left(0,5 \mathrm{~g} \mathrm{~L}^{-1}\right), \mathrm{NaNO}_{3}\left(3,0 \mathrm{~g} \mathrm{~L}^{-1}\right), \mathrm{FeSO}_{4} \cdot 7 \mathrm{H}_{2} \mathrm{O}\left(0,01 \mathrm{~g} \mathrm{~L}^{-1}\right), \mathrm{K}_{2} \mathrm{HPO}_{4}\left(1,0 \mathrm{~g} \mathrm{~L}^{-1}\right)$, ágar $\left(15,0 \mathrm{~g} \mathrm{~L}^{-1}\right)$. Em seguida, os rizóbios foram incubados em B.O.D. a $28 \pm 2^{\circ} \mathrm{C}$ durante 10 dias. Depois desse período, em cada placa de Petri, adicionaram-se $10 \mathrm{~mL}$ de vermelho congo $\left(1 \mathrm{~g} \mathrm{~L}^{-1}\right)$. A solução agiu durante 15 minutos a $25^{\circ} \mathrm{C}$. Retirou-se $\mathrm{O}$ excesso da solução de corante e, em cada placa, adicionaram-se $10 \mathrm{~mL}$ de $\mathrm{NaCl}$ $(1 \mathrm{M})$, a qual agiu durante 30 minutos a $25^{\circ} \mathrm{C}$. Posteriormente, retirou-se o excesso da solução de cloreto de sódio e observou-se a presença de halos de degradação em volta das colônias de rizóbios. A formação do halo caracterizou a positividade do teste.

\section{Atividade amilolítica}

A produção de amilase foi determinada segundo método descrito por COON et al. (1957), com algumas modificações. As cepas foram inoculadas em meio composto de: peptona $\left(10,0 \mathrm{~g} \mathrm{~L}^{-1}\right)$, extrato de carne $\left(3,0 \mathrm{~g} \mathrm{~L}^{-1}\right), \mathrm{NaCl}\left(5,0 \mathrm{~g} \mathrm{~L}^{-1}\right)$, ágar $\left(15,0 \mathrm{~g} \mathrm{~L}^{-1}\right)$, amido $\left(2,0 \mathrm{~g} \mathrm{~L}^{-1}\right)$. Após a inoculação, o tempo de incubação das cepas em B.O.D. a $28 \pm 2^{\circ} \mathrm{C}$, foi de 10 dias. Em cada placa de Petri, adicionaram-se $10 \mathrm{~mL}$ de lugol ( $1 \%$ iodo em $2 \%$ iodeto de potássio). A formação do halo caracterizou a positividade do teste. 


\section{Atividade lipolítica}

A produção de lipase foi analisada com base no método proposto por SIERRA (1957). As cepas de rizóbio foram inoculadas em um agente solidificante formado de: peptona bacteriológica $\left(10,0 \mathrm{~g} \mathrm{~L}^{-1}\right), \mathrm{NaCl}\left(5,0 \mathrm{~g} \mathrm{~L}^{-1}\right), \mathrm{CaCl}_{2} \cdot 2 \mathrm{H}_{2} \mathrm{O}(0,1 \mathrm{~g}$ $\left.\mathrm{L}^{-1}\right)$, ágar $\left(15,0 \mathrm{~g} \mathrm{~L}^{-1}\right)$, Tween $80\left(10 \mathrm{~mL} \mathrm{~L}^{-1}\right)$. Durante 10 dias, as cepas foram incubadas em B.O.D. a $28 \pm 2^{\circ} \mathrm{C}$. Após o crescimento das colônias, os halos foram medidos.

\section{Índice enzimático}

A atividade enzimática foi expressa através do índice enzimático (IE), determinado pela equação $\mathrm{IE}=\mathrm{Dh} / \mathrm{Dc}$. Onde $\mathrm{Dh}$ compreende o diâmetro em milímetros $(\mathrm{mm})$ do halo de hidrólise e Dc corresponde ao diâmetro em $\mathrm{mm}$ da colônia de rizóbios (FLORENCIO et al., 2012).

\section{Análise estatística}

Para a atividade celulolítica, amilolítica e lipolítica, realizaram-se dois ensaios independentes (duplicata), cada um em quadruplicata, obtendo-se assim oito valores de diâmetro do halo e da colônia. A partir desses valores, o IE médio e o desvio padrão foram calculados, para cada cepa de rizóbio. Tais dados foram submetidos ao teste de normalidade, utilizando-se o software estatístico Action 2.9. Após a análise estatística, com base na normalidade, com o auxilio do software estatístico Prism 5.0, aplicou-se o teste não paramétrico Kruskal-Wallis test.

\section{RESULTADOS E DISCUSSÃO}

O halo indicador de hidrólise da carboximetilcelulose, do amido e do Tween 80 é caracterizado pela área mais clara ao redor da colônia. A formação de halo indicativo da degradação da carboximetilcelulose foi observada em 25 cepas, $(59,5 \%)$ dos rizóbios estudadas. Todas as cepas de rizóbios apresentaram halo de hidrólise do amido. No caso da atividade lipolítica, 15 cepas de rizóbios analisadas $(35,7 \%)$ formaram halo de precipitação (Tabela 1$)$.

A atividade amilolítica foi mais expressiva do que a atividade celulolítica o que pode estar associado à maior complexidade da celulose em relação ao amido. CRAGG et al. (2015) afirmaram que a cristalinidade da celulose é um obstáculo para a ação de enzimas, dificultando o acesso das mesmas, enquanto que IRFAN et al. (2012) relataram que a natureza insolúvel e a estrutura cristalina da celulose dificultam a degradação.

TABELA 1 Índice enzimático (IE) de cepas de rizóbio oriundas da região semiárida

\begin{tabular}{cccc}
\hline & Celulose & Amilase & Lipase \\
\hline Cepas de rizóbios & & IE (Dh/Dc) & \\
\hline L31 & 1,174 & 3,886 & - \\
L32 & 1,444 & 5,447 & - \\
L33 & - & 2,614 & 2,802 \\
L35 & 1,226 & 5,741 & - \\
L36 & - & 6,480 & 1,349 \\
L37 & - & 3,777 & - \\
L38 & - & 3,296 & -
\end{tabular}




\begin{tabular}{cccc} 
L39 & 1,578 & 3,240 & - \\
L40 & 1,640 & 5,043 & 1,244 \\
L41 & - & 2,644 & 2,484 \\
L42 & 2,415 & 4,656 & - \\
L43 & - & 4,633 & - \\
L46 & 1,951 & 5,197 & 1,487 \\
L47 & 1,911 & 3,531 & 1,538 \\
L48 & 1,689 & 3,806 & 1,523 \\
L49 & - & 2,834 & - \\
L51 & - & 4,305 & - \\
L52 & - & 3,230 & - \\
L53 & 1,286 & 4,818 & - \\
L54 & 2,359 & 4,021 & - \\
L56 & 2,615 & 4,372 & - \\
L59 & 1,669 & 4,261 & 2,190 \\
L60 & - & 8,079 & 1,907 \\
L62 & - & 2,864 & - \\
L63 & - & 3,708 & - \\
L64 & 1,665 & 2,822 & 2,255 \\
L65 & 2,144 & 5,795 & - \\
L66 & 1,461 & 3,060 & - \\
L67 & 1,572 & 4,267 & 2,437 \\
L69 & 1,867 & 3,239 & - \\
L70 & 2,031 & 3,657 & 0,769 \\
L71 & 2,640 & 4,870 & 1,220 \\
L72 & - & 3,170 & 4,314 \\
L73 & 2,016 & 3,883 & - \\
L74 & - & 4,316 & 2,810 \\
L76 & 2,204 & 2,647 & - \\
L77 & 1,959 & 3,013 & - \\
L78 & - & 4,551 & - \\
L79 & 1,886 & 3,475 & - \\
L80 & - & 1,891 & - \\
L81 & - & 3,574 & - \\
L82 & 1,744 & 3,473 & \\
\hline L8 & & & - \\
\hline-1969 & - \\
\hline
\end{tabular}

(-) não houve formação de halo.

SILVA et al. (2015a), ao avaliarem a atividade celulolítica e amilolítica de 28 cepas de actinobactérias dos gêneros Streptomyces, Terrabacter, Nocardia e Micromonospora isoladas a partir do solo do Parque Nacional de Ubajara (CE), relataram que $75 \%$ das cepas produziram celulase e que $82 \%$ produziram amilase. Tais autores sugeriram que o menor percentual de produção de celulase, em comparação à amilase, pode ser atribuído à maior complexidade química da celulose.

A produção de amilase foi observada em todas as cepas de rizóbios, o que também foi relatado por CHANDRA (2016) ao avaliar a atividade amilolítica de 
cepas de rizóbios oriundos de nódulos de raízes de leguminosas na Índia. Resultados semelhantes foram obtidos por FERNANDES JÚNIOR et al. (2012) que registraram a atividade amilolítica das 27 cepas de rizóbios obtidos de nódulos de feijão-guandu (Cajanus cajan). Esses autores classificaram a produção de amilase em alta $(1,5 \leq \mathrm{IE}<2,0)$, intermediária $(1,0 \leq \mathrm{IE}<1,5)$ e baixa $(\mathrm{EI} \leq 1,0)$, sendo que verificaram alta produção de amilase extracelular em quatro dos isolados avaliados, dos quais um apresentou IE maior que 3,5; quatro isolados com produção intermediária desta enzima e 19 isolados com baixa atividade enzimática extracelular.

No presente trabalho, seguiu-se a escala do índice enzimático estabelecido por SILVA et al. (2015a) e as cepas de rizóbios foram classificadas, quanto à intensidade de produção de enzimas, utilizando o IE como parâmetro, em cepas fracamente $(1,0 \leq \mathrm{IE}<1,5)$, moderadamente $(1,5 \leq \mathrm{IE}<2,0)$, fortemente (IE $\geq$ 2) e não produtoras (IE $=0$ ) de celulase, de amilase e de lipase.

Por essa classificação, cinco cepas mostraram-se fracamente produtoras $(1,0 \leq \mathrm{IE}<1,5)$ (L31, L32, L35, L53 e L66, 11,9\%), 12 cepas moderadamente produtoras $(1,5 \leq \mathrm{IE}<2,0)$ (L39, L40, L46, L47, L48, L59, L64, L67, L69, L77, L79 e L82, 28,6\%), 8 cepas fortemente produtoras (IE $\geq 2$ ) (L42, L54, L56, L65, L70, L71, L73 e L76, 19,0\%) e 17 cepas não produziram celulase (IE = 0) (L33, L36, L37, L38, L41, L43, L49, L51, L52, L60, L62, L63, L72, L74, L78, L80 e L81, 40,5\%) (Figura 1). Esses dados corroboram com OLIVEIRA et al. (2006) que analisando a atividade celulolítica de 67 cepas de rizóbios obtidos da rizosfera sob influência de leguminosas, no Estado do Amazonas, registraram que a maioria das cepas de rizóbios foram classificadas como moderadamente produtoras de celulase. Tais autores relataram produção de celulase por 6 cepas, sendo que $5(83,33 \%)$ apresentaram-se moderadamente produtoras, enquanto que apenas a cepa INPA R$922(16,67 \%)$ caracterizou-se como fortemente produtora de celulase.



FIGURA 1. Nível de produção de celulase, em função do índice enzimático das cepas de rizóbios provenientes da Fazenda Experimental Vale do Curu. 
Em relação a amilase apenas uma cepa mostrou-se moderadamente produtora $(1,5 \leq \mathrm{IE}<2,0)(\mathrm{L} 80,2,38 \%)$ e 41 cepas fortemente produtoras (IE $\geq 2)$ (L31, L32, L33, L35, L36, L37, L38, L39, L40, L41, L42, L43, L46, L47, L48, L49, L51, L52, L53, L54, L56, L59, L60, L62, L63, L64, L65, L66, L67, L69, L70, L71, L72, L73, L74, L76, L77, L78, L79, L81, L82, 97,62\%) (Figura 2).

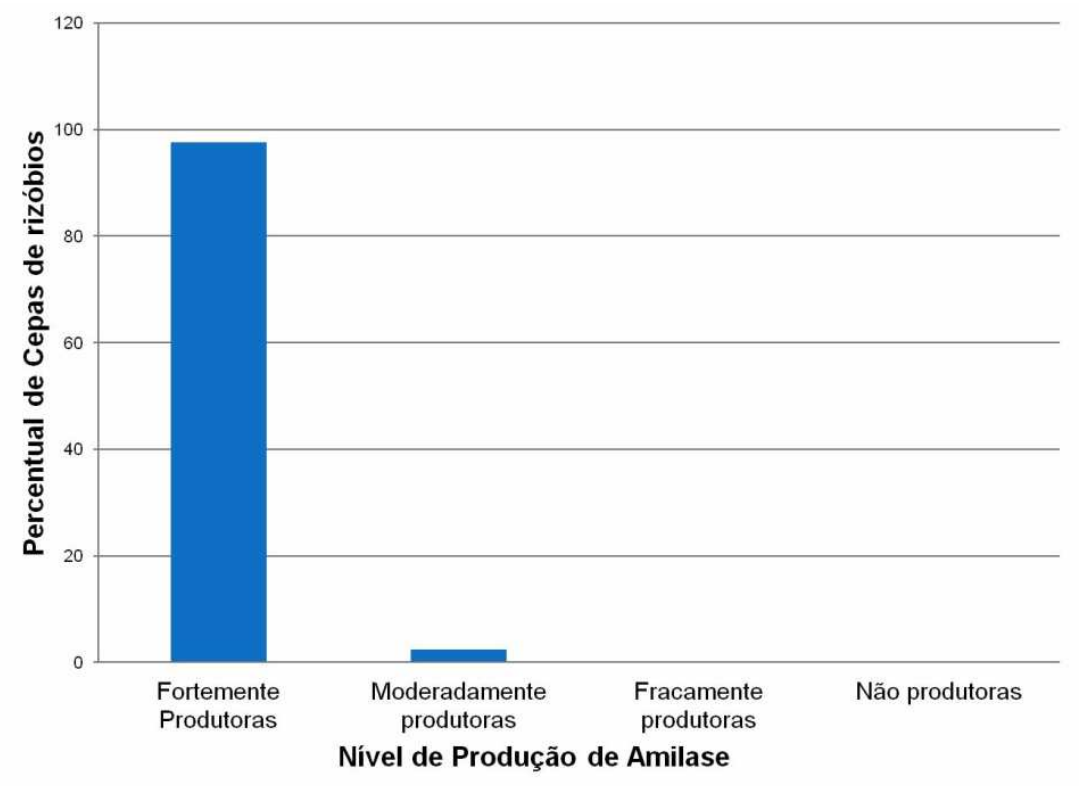

FIGURA 2. Nível de produção de amilase, em função do índice enzimático das cepas de rizóbios provenientes da Fazenda Experimental Vale do Curu.

Enzimas como a urease, protease, amilase, gelatinase exercem uma função importante durante a formação de nódulos. As cepas que produzem estas enzimas são consideradas melhores para a nodulação e a fixação de nitrogênio (KUMARI et al., 2010). A atividade celulolítica em cepas de rizóbios é relevante à simbiose, uma vez que a simbiose entre leguminosa e rizóbio e, tais bactérias nodulíferas produzem celulases em alguma intensidade (ROBLEDO et al., 2008).

Os resultados para lipase demonstraram 5 cepas fracamente produtoras de lipase $(1,0 \leq \mathrm{IE}<1,5)$ (L36, L40, L46, L70 e L71, 11,9\%), 3 cepas moderadamente produtoras $(1,5 \leq \mathrm{IE}<2,0)$ (L47, L48, L60, 7,14\%), 7 cepas fortemente produtoras (IE $\geq 2$ ) (L33, L41, L59, L64, L67, L72 e L74, 16,67\%) e 27 cepas não produziram lipase (IE $=0$ ) (L31, L32, L35, L37, L38, L39, L42, L43, L49, L51, L52, L53, L54, L56, L62, L63, L65, L66, L69, L73, L76, L77, L78, L79, L80, L81 e L82, 64,29\%). OLIVEIRA et al. (2006), verificando a produção de lipase de 67 cepas de rizóbios da rizosfera de plantas como feijão e mandioca, no Estado do Amazonas, relataram que somente três cepas produziram lipase e as mesmas mostraram-se fracamente produtoras. 


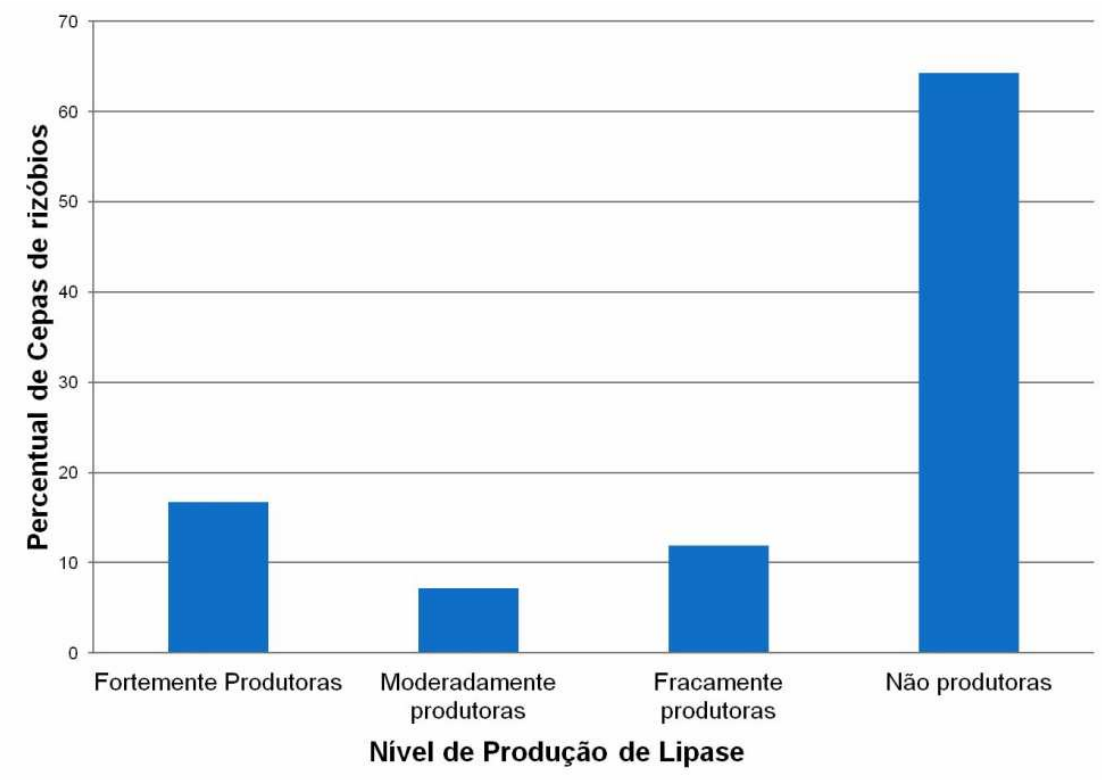

FIGURA 3. Classificação da intensidade de produção de lipase, em função do índice enzimático das cepas de rizóbios provenientes da Fazenda Experimental Vale do Curu.

Micro-organismos produtores de lipases desempenham função relevante em setores industriais como alimentos e de cosméticos (HASAN et al., 2006). As lipases podem ser utilizadas na promoção de crescimento da planta (SOUSA et al., 2008), bem como pelos micro-organismos como mecanismos de defesa (STEHR et al., 2003).

Uma vez que os dados não seguiram uma distribuição normal, foi aplicado o teste de médias (Kruskal-Wallis test), por meio do qual se observou diferença significativa entre as médias dos índices enzimáticos das cepas analisadas no teste de atividade celulolítica $(P=1,05 \mathrm{E}-05)$, amilolítica $(P=0,015133)$ e lipolítica $(P=5,83 \mathrm{E}-08)$.

A produção de amilase $(97,62 \%)$ foi mais expressiva do que a produção de celulase (19\%), e esta superior a produção de lipase (16,67\%), corroborando com OLIVEIRA et al. (2006), que ao analisarem a atividade amilolítica, celulolítica e lipolítica de 67 cepas de rizóbio oriundos da Amazônia Central, também observaram esse comportamento, a produção de amilase $(32,8 \%)$, de celulase $(9,0 \%)$ e de lipase $(4,5 \%)$. Comparando esses resultados com os observados no presente estudo, sugere-se a superioridade do potencial enzimático, principalmente, amilolítico das cepas de rizóbios da Fazenda Experimental Vale do Curu.

O IE referente à produção de celulase, de 42 cepas de rizóbios variou de 1,17 (L31) a 2,64 (L71), enquanto que, referente à produção de amilase, variou de 1,89 (L80) a 8,08 (L60). Considerando a atividade lipolítica, IE variou de 0,77 (L70) a 4,31 (L72) (Tabela 1). Segundo FLORÊNCIO et al. (2012), as cepas com IE maior que 1,50 classificam-se como potenciais produtoras de enzimas, assim, observa-se que $47,6 \%$ dos rizóbios estudados podem ser qualificadas produtoras de celulase, $100 \%$ de amilase e, $23,8 \%$ de lipase.

Os resultados para as atividades enzimáticas variaram entre os isolados, o que está de acordo com os resultados obtidos por KUMARI et al. (2010) que 
analisaram a produção de 13 enzimas, incluindo a amilase e a lipase, por cepas de rizóbios isolados de nódulos de cinco espécies do gênero Indigofera, e, relataram muita variação quanto à produção dessas enzimas.

Devido ao papel preponderante das enzimas hidrolíticas nos processos ecológicos, com destaque aos dados obtidos com o estudo para cepas do semiárido, os resultados contribuem para o aprofundamento dos estudos para esse bioma e expõem o potencial dessas cepas para diferentes finalidades.

\section{CONCLUSÃO}

As cepas de rizóbio apresentaram atividade enzimática, com predomínio de produção de amilase $(97,62 \%)$, seguida por produção de celulase $(19 \%)$ e lipase $(16,67 \%)$. Destaca-se a cepa L60 (IE = 8,08) como fortemente produtora de amilase.

\section{REFERÊNCIAS}

CHANDRA, K. K. Morphological and biochemical activities of root nodule Rhizobium isolated from five multipurpose forest species of India. International Journal of Plant \& Soil Science, v. 10, n.3, p. 1-6, 2016. Disponível em: $<$ http://dx.doi.org/10.9734/IJPSS/2016/23340>. doi: 10.9734/IJPSS/2016/23340

CHARBONNEAU, D. M., MOUELHI, F. M., BOISSINOT, M., SIROIS, M., BEAUREGARD, M. Identification of thermophilic bacterial strains producing thermotolerant hydrolytic enzymes from manure compost. Indian Journal of Microbiology, v.52, n.1, p. 41-47, 2012. Disponível em: <http://dx.doi.org/10.1007/s12088-011-0156-8>. doi: 10.1007/s12088-011-0156-8

COMPANT, S.; CLÉMENT, C.; SESSITSCH, A. Plant growth-promoting bacteria in the rhizo and endosphere of plants: Their role, colonization, mechanisms involved and prospects for utilization. Soil Biology \& Biochemistry, v.42, n.5, p.669-678, 2010. Disponível em: <http://dx.doi.org/10.1016/j.soilbio.2009.11.024>. doi: 10.1016/j.soilbio.2009.11.024

COON, H.J., JENNISON, M.W. \& WEEK, O.B. Routine tests for the identification of bacteria. In: Society of American Bacteriologists ed. Manual of Microbiological Methods. New York. McGraw-Hal, p.239-262, 1957.

CRAGG, S.M; BECKHAM, G.T.; BRUCE, N.C.; BUGG, T.D.H.; DISTEL, D.L.; DUPREE, P.; ETXABE, A.G.; GOODELL, B.S.; JELLISON, J.; MCGEEHAN, J.E.; MCQUEEN-MASON, S.J.; SCHNORR, K.; WALTON, P.H.; WATTS, J.E.M.; ZIMMER, M. Lignocellulose degradation mechanisms across the Tree of Life. Current Opinion in Chemical Biology, v.29, p.108-119, 2015. Disponível em: <http://dx.doi.org/10.1016/j.cbpa.2015.10.018>. doi: 10.1016/j.cbpa.2015.10.018.

EMBRAPA. Centro Nacional de Pesquisa de Solos. Sistema brasileiro de classificação de solos. Brasília, DF: Embrapa Produção da Informação; Rio de Janeiro: Embrapa Solos, 1999. 412 p. 
FERNANDES JUNIOR, P. I.; LIMA, A. A. de; PASSOS, S. R.; GAVA, C. A. T.; OLIVEIRA, P. J. de; RUMJANEK, N. G.; XAVIER, G. R. Phenotypic diversity and amylolytic activity of fast growing rhizobia from pigeonpea [Cajanus cajan (L.) Millsp.]. Brazilian Journal of Microbiology, v .43, n. 4, p. 1604-1612, 2012. Disponível em: <http://dx.doi.org/10.1590/S1517-83822012000400045>. doi: 10.1590/S1517-83822012000400045

FLORENCIO, C., COURI, S., FARINAS, C. S. Correlation between agar plate screening and solid-state fermentation for the prediction of cellulase production by Trichoderma strains. Enzyme Research, p.1-7, 2012. Disponível em: <http://dx.doi.org/10.1155/2012/793708>. doi: 10.1155/2012/793708

HANKIN, L., ANAGNOSTAKIS, S. L. Solid media containing carboxy methylcellulose to detect cellulase activity of microorganisms. Journal of General Microbiology, v.98, n.1, p. 109-115, 1977. Disponível em: <http://dx.doi.org/10.1099/00221287-981-109>. doi: 10.1099/00221287-98-1-109

HASAN, F.; SHAH, A. A.; HAMEED, A. Industrial applications of microbial lipases. Enzyme and Microbial Technology, v.39, n.2, p.235-251, 2006. Disponível em: <http://dx.doi.org/10.1016/j.enzmictec.2005.10.016>. 10.1016/j.enzmictec.2005.10.016

doi:

IRFAN, M.; ASMA, S.; QURATULAIN, S.; MUHAMMAD, N. Isolation and screening of cellulolytic bacteria from soil and optimization of celulase production and activity. Turkish Journal of Biochemistry, v.37, n.3, p.287-293. Disponível em: <http://dx.doi.org/10.5505/tjb.2012.09709>. doi: 10.5505/tjb.2012.09709

JARALLA, E.M., AL-DABBAGH, N.N., HAMEED, N.M., ABDUL-HUSSAIN, N. Screening for enzymatic production ability and antimicrobial activity of actinomycetes isolated from soil in Hillah/Iraq. Journal of Pharmacy and Biological Sciences, v.9, n.5, p.42-47, 2014. Disponível em: <http://dx.doi.org/10.9790/3008-09564247>. doi: $10.9790 / 3008-09564247$

KUMARI, B.S.; RAM, M.R.; MALLAIAH, K.V. Studies on nodulation, biochemical analysis and protein profiles of Rhizobium isolated from Indigofera species. Malaysian Journal of Microbiology, v. 6, n. 2, p.133-139, 2010. Disponível em: <http://journaldatabase.info/articles/studies_on_nodulation_biochemical.html>.

LIMA, B.G.; COELHO; M.F.B.; OLIVEIRA, O.F. Caracterização florística de duas áreas de caatinga na região centro-sul do Ceará, Brasil. Bioscience Journal, v. 28, n.2, p. 277-296, 2012. Disponível em: <http://www.seer.ufu.br/index.php/biosciencejournal/article/view/12525/8490>.

LONGATTI, S. M. O.; MARRA, L. M.; MOREIRA, F. M. S. Evaluation of plant growth promoting traits of Burkholderia and Rhizobium strains isolated from Amazon soils for their co-inoculation in common bean. African Journal of Microbiology Research, v.7, n.11, p.948-959, 2013.2 Disponível em: <http://dx.doi.org/10.5897/AJMR12.1055>. doi: 10.5897/AJMR12.1055 
MAGESWARI, A.; SUBRAMANIAN, P.; CHANDRASEKARAN, S.; SIVASHANMUGAM, K.; BABU, S.; GOTHANDAM, K.M. Optimization and immobilization of amylase obtained from halotolerant bacteria isolated from solar salterns. Journal of Genetic Engineering and Biotechnology, v.10, n.2, p. 201 208, 2012. Disponível em: <http://dx.doi.org/10.1016/j.jgeb.2012.09.001>. doi: 10.1016/j.jgeb.2012.09.001

MOREIRA, F.M. S.; SIQUEIRA, J. O. Microbiologia e Bioquímica do Solo. Lavras: UFLA, 2006.

OLIVEIRA, A. N.; OLIVEIRA, L.A.; ANDRADE, J.S.; CHAGAS JÚNIOR, A.F. Atividade enzimática de isolados de rizóbios nativos da Amazônia central crescendo em diferentes níveis de acidez. Ciência, tecnologia e alimentos, v. 26, n.1, p. 204210, 2006. Disponível em: <http://dx.doi.org/10.1590/S0101-20612006000100032>. doi: 10.1590/S0101-20612006000100032

PAIVA, C. L. A.; SÁ-PEREIRA, P. A aplicação da Biologia Molecular no aprimoramento da produção de enzimas. In: BON, E. P. S.; FERRARA, M. A. A.; CORVO, M. L. (Eds.). Enzimas em Biotecnologia: produção, aplicações e mercado. Rio de Janeiro: Interciência, p. 29-53, 2008.

PAUL, D. Microorganisms and a-amylase: a concise review. Innovare Journal of Science, v.4, n.4, p.1-5, 2016. Disponível em: <http://innovareacademics.in/journals/index.php/ijs/article/view/13509/pdf>.

ROBLEDO, M.; JIMÉNEZ-ZURDO, J. I.; VELÁZQUEZ, E.; TRUJILLO, M. E.; ZURDO-PIÑEIRO, J. L.; RAMÍREZ-BAHENA, M. H.; RAMOS, B.; DÍAZ MÍNGUEZ, J. M.; DAZZO, F.; MARTÍNEZ-MOLINA, E.; MATEOS, P. F. Rhizobium cellulase $\mathrm{CelC}_{2}$ is essential for primary symbiotic infection of legume host roots. Proceedings National Academy of Sciences of the United States of America, v. 19, n. 105, p. 7064-7069, 2008. Disponível em: <http://dx.doi.org/10.1073/pnas.0802547105>. doi: 10.1073/pnas.0802547105

SABINO, D.C.C.; FERREIRA, J.S.; GUIMARÃES, S.L.; BALDANI, V.L.D. Bactérias diazotróficas como promotoras do desenvolvimento inicial de plântulas de arroz. Enciclopédia Biosfera, v.8, n.15, p. 2337-2345, 2012. Disponível em: <http://www.conhecer.org.br/enciclop/2012b/ciencias\%20biologicas/bacterias.pdf>.

SAMPATHKUMAR, S.; ASHWINI, K. Isolation and screening of potent amylaseproducing marine actinomycetes from seabed. Malaya Journal of Biosciences, v.1, n.4, p.273-276, 2014. Disponível em: $<$ http://malayabiosciences.com/articles/10._Ahswhini_et_al.-_MJB_1(4)_273276.pdf>.

SATHYA, R.; USHADEVI, T. Industrially important enzymes producing Streptomyces species from mangrove sediments. International Journal of Pharmacy and Pharmaceutical Sciences, v.6, p.233-237, 2014. Disponível em: <http://innovareacademics.in/journals/index.php/ijpps/article/view/2588>. 
SIERRA, S. A. Simple method for detection of lipolytic activity of microorganisms and some observations on the influence of the contact between cells and fatty substrates. Antonie van Leeuwenhoek, v. 23, n.1, p.15-22, 1957. Disponível em: <http://dx.doi.org/10.1007/BF02545855>. doi: 10.1007/BF02545855

SILVA, V.M.A; BRITO, F.A.E.; RAMOS, K.A.; SILVA, R.M.; MARTINS, C.M.; MARTINS, S.C.S. Atividade enzimática de actinobactérias do semiárido. Revista Brasileira de Geografia Física, v. 8, número especial IV SMUD, p. 560-572, 2015a. Disponível <http://www.revista.ufpe.br/rbgfe/index.php/revista/article/view/1470/754>.

em:

SILVA, V.M.A.; MARTINS, C.M.; MARTINS, S.C.S. Atividade celulolítica de actinobactérias de região semiárida do Ceará. Enciclopédia Biosfera, v.11 n.21, p.2026-2036, 2015b. Disponível em: <http://www.conhecer.org.br/enciclop/2015b/biologicas/atividade\%20celulolitica.pdf>.

SOUSA, C.S.; SOARES, A.C.F.; GARRIDO, M.S. Caracterização de estreptomicetos com potencial para promoção de crescimento de plantas e biocontrole. Scientia Agrícola, v. $65, \quad$ n. 1, p. 50-55, 2008. Disponível em: <http://dx.doi.org/10.1590/S0103-90162008000100007>. doi: 10.1590/S010390162008000100007

SOUSA, J.B.; PINHEIRO, M.S.; SILVA, L.L.; MARTINS, S.C.S.; MARTINS, C.M. Caracterização de bactérias nativas de solo do semiárido isoladas de nódulos de feijão-caupi. Enciclopédia Biosfera, v.10, n. 19, p. 2797-2806, 2014. Disponível em: <http://conhecer.org.br/enciclop/2014b/MULTIDISCIPLINAR/Caracterizacao\%20de\% 20bacterias.pdf>.

STEHR, F.; KRETSCHMAR, M.; KRÖGER, C.; HUBE, B.; SCHÄFER, W. Microbial lipases as virulence factors. Journal of Molecular Catalysis B: Enzymatic, v. 22, n.5-6, p. 347-355, 2003. Disponível em: http://dx.doi.org/10.1016/S13811177(03)00049-3>. doi: 10.1016/S1381-1177(03)00049-3

STOYANOVA, V.; GEORGIEVA, S.; ILIEV, I.; MARHOVA, M.; TRIFONOVA, S. Lipolytic activity of genus Pseudomonas. Journal of Bioscience and Biotechnology, v.19-20, p.163-168, 2012. Disponível em: <http://www.jbb.uniplovdiv.bg/documents/27807/178249/SE-2012-163-168.pdf/>.

SUPERINTENDÊNCIA DO DESENVOLVIMENTO DO NORDESTE (SUDENE). Disponível em: <http://www.sudene.gov.br/acesso-ainforma\%C3\%A7\%C3\%A3o/institucional/area-de-atuacao-da-sudene/semiarido> Acesso em: 15/09/2016.

VAN DER SAND, S.T.; MINOTTO, E.; MILAGRE, L.P.; OLIVEIRA, M.T. Enzyme characterization of endophytic actinobacteria isolated from tomato plants. Journal of Advanced Scientific Research, v.5, n.2, p.16-23, 2014. Disponível em: <http://www.sciensage.info/journal/1401240027JASR_0302141.pdf>. 